\title{
Different Grouping Strategies for Cooperative Learning in English Majored Seniors and Juniors at Can Tho University, Vietnam
}

\author{
Hien Nhan ${ }^{1}$ and Thái Anh Nhan ${ }^{2, *}$ \\ 1 Gia Viet English Center, 39 Mau Than, Can Tho city, Vietnam; nhanthaihien@gmail.com \\ 2 Department of Mathematics and Science, Holy Names University, 3500 Mountain Blvd., Oakland, \\ CA 94619, USA \\ * Correspondence: nhan@hnu.edu; Tel.: +1-510-436-1281
}

Received: 1 January 2019; Accepted: 9 March 2019; Published: 14 March 2019

\begin{abstract}
We present research on the attitudes of seniors and juniors doing a major in English toward different grouping strategies for cooperative learning at Can Tho University, Can Tho city, Vietnam. The collected data is analyzed by a means of quantitative approach. The findings not only facilitate the further understanding of English majors' opinions on different grouping strategies, but also provide teachers and lecturers who employ cooperative learning as one of their teaching strategies with useful clues on which group formation they should use. More importantly, we hope to give an insight to the characteristics of different grouping strategies, in order to find out the group forming method(s) that simultaneously boosts group dynamics, students' satisfaction, and academic achievements.
\end{abstract}

Keywords: cooperative learning; grouping strategies; quantitative analysis

\section{Introduction}

Language is a tool humans use to exchange information. Language acquisition is the process by which people acquire the ability to perceive and understand, as well as to produce utterances to communicate. To naturally acquire a language, particularly English, one needs engagement, a lot of practice and authentic language contexts. A successful language classroom is the one that encourages students' engagement, maximizes their practice time and allows socialization. Cooperative learning is an active pedagogy which has long been proven to be a means of promoting learning by encouraging the use of cognitive-strategies of higher level, critical thinking, and positive attitude towards learning in students (Hsu [1]; Johnson and Johnson [2,3]). Hence, cooperative learning is one of the most widespread educational approaches in language teaching, especially in teaching English (see, for instance, $[4,5]$ and the monograph by McCafferty et al. [6]).

Cooperative learning has become increasingly common in classrooms at Can Tho University-a multidisciplinary university and a leading university in the Mekong Delta, South of Vietnam, with a population of 45,000 students. In particular, the School of Education provides the essential training for future teachers in nine different subjects ranging from mathematics to English. Collaborative learning activities employed in these classrooms, which usually require students to work together, are assigned regularly and they usually make up 10 to up to 80 percent of the final grade. It is essential that students, as well as lecturers, take a serious look at the factors that decide the effectiveness of cooperative learning. Although there is a lot of research on the effect of cooperative learning, little is known about the impact of group formation on the outcome of team-working of education students at Can Tho University, especially English majors. 
Taking all the discussed issues into consideration, the researchers decided to carry out an investigation into the attitudes of seniors and juniors with majors in English toward different grouping strategies for cooperative learning with a strong belief that adequate knowledge of students' preferences on grouping strategies can help promote the effectiveness of cooperative learning in terms of group dynamics, learners' satisfaction and achievements. This study intends to investigate four different grouping strategies for cooperative learning: student-selected groups (in which students choose partners themselves), randomly-assigned groups (in which teachers group students randomly), homogeneously-assigned groups (in which teachers purposefully group students with the same academic level, skills, and background in one group), and heterogeneously-assigned groups (in which teachers purposefully group students with different academic level, skills, and background in one group). While student-selected groups are ubiquitous, the significance of the other three remains undetermined in the context of English classrooms.

These researchers not only aim to facilitate better cooperative learning in English classrooms by giving insights into the effects of group formation on the cooperative learning experience of students, but also provides a general understanding on the affect of grouping strategies in the School of Education. Furthermore, it hopes to provide meaningful data for course designers who see working in teams as one of the skills that students should be taught during their undergraduate course. Additionally, we would like to investigate whether the four group formation methods made a difference in terms of perception on group dynamics, student's satisfaction, and achievements. Using this specific group of the English majors as a representative of a broader population of Can Tho University students, our finding can be applied to other majors of the School of Education which educates teachers in nine different disciplines.

The paper is organized as follows. We begin with a review of the research literature on cooperative learning and grouping strategies in Section 2. Then the research methodology is carefully described in Section 3. The results and discussions of the findings are reported in Sections 4 and 5, respectively. Finally, we conclude the paper with several remarks and recommendations in Section 6.

\section{A Brief Review of the Research Literature}

\subsection{Cooperative Learning}

"Cooperative learning" or "collaborative learning" is now a prevalent trend in language classrooms, especially English classrooms. The terms are also regarded as generic descriptions for certain procedures and instructional techniques that involve the conceptual learning and social development of students. According to Kagan [7], cooperative learning is a teaching arrangement that refers to small, heterogeneous group of students working together to achieve a common goal. Two is better than one, just not always. Not every group of students put together is considered cooperative or collaborative. In their paper on making cooperative learning work, Johnson and Johnson [3] (p. 68) made clear that: "Some kinds of learning groups facilitate student learning and increase the quality of life in the classroom. Other types of learning groups hinder student learning and create disharmony and dissatisfaction". Taken that into account, educators must be aware of the basic elements of structuring cooperative learning groups. One of the important factors that contributes to effective cooperating learning is the peer effects. It is suggested that group formation and variation in group inputs (member abilities/skills/relations) nurture different types of group interactions and outcome (Hishina, Okada and Suzuki [8]). The act of putting students in groups or choosing the peers, therefore, is essential to successful cooperative learning. Group formation varies from natural variation (grouping randomly) to optimal policy (grouping based on some specific criteria). The most common grouping models are instructor-assigned groups (randomly or with systematic allocation, homogeneously or heterogeneously) and student-selected groups. The effect of group experience, or how well students perform working together in groups, is often measured using performance 
outcomes like grades on projects, tests, and exams. Students' social interactions and group dynamics while learning cooperatively, on the other hand, seem to be less considered, or graded.

\subsection{Student-Selected Groups}

Student-selected groups are ubiquitous and seem to be favored by students. In student-selected groups, students choose their collaborators themselves with little to no intervention made by the educators. The educators usually announce the desired number of students in a single group and let the students form the group accordingly. Typically, the individuals who seek student-selected groups are high achieving and have had prior social or academic interactions with one another (Chapman, Meuter, Toy and Wright [9]; Swanson, Gross and Kramer [10]). On the characteristics of student-selected groups, Swanson et al. [10] carried out an analysis of the relation between the methods of study group formation and student performance. Their findings indicated that individuals in groups formed of their own accord outperformed those in groups formed by assignment. One possible reason suggested to explain their result is that the familiarity among members in self-selected groups may have made it easier for them to communicate with each other. The high frequency of meetings for discussion due to compatible schedules also created plenty opportunities for information exchange. Similar conclusions have been drawn by Chapman et al. [9], who conducted an experiment on marketing students at a residential American Assembly of Collegiate Schools of Business (AACSB) to assess the two most commonly used methods of cooperative learning: self-selected and random assignment (i.e., student-selected and randomly-assigned). The experiment responses suggested that members of student-selected groups were generally better at getting along, communicating, and were more enthusiastic about working together. However, they appeared to be less task oriented than the members from groups formed by other grouping methods. However, a survey administrated by Feichtner and Davis [11] showed that the worst group experience was more likely to be linked with student-selected groups: "Specifically, in recording information concerning their worst group experience, 40 percent of the respondents noted that the groups were formed by the students themselves, while in the best group experience, only 22 percent reported that the students were responsible for forming the groups" [11] (p. 60). Several open-ended questions from this survey provided some insights to the problems encountered by letting students create their own group. For instance, one student reported on feeling left-out as she was the only person who did not belong to a sorority. Another member from a student-selected group regretted not having a person who is good at computer on the team and viewed the fact as a disadvantage. The result of this survey helped Feichtner and Davis [11] came up with a set of tactics for productive cooperative learning, with the advice against allowing students to form their own group or freely make homogeneous group written at the top of the list.

\subsection{Randomly-Assigned Groups}

Randomly-assigned learning groups are groups in which the members are put together randomly. Simple random assignment allocates students to groups with regard only to final group size (Hilton and Phillips [12]). For example, students may be assigned to the same group if they sit next to each other in class, or the teachers may randomly number them and put students with the same number in one group. This simple strategy is commonly used in the classrooms that do not require prerequisites [13]. The first notable advantage of this method is that it seems fair and unbiased because the chances of being selected to one group is equal for every student. This also eliminates the chance of some isolated students fail to participate in a group. Practicing this type of grouping also takes less effort since no or little preparation or research on students' background is needed for random grouping. However, in the reality of classroom teaching, there may be preexisting attributes that make randomly assigned groups less or no longer random. For instance, students with the same ability tend to sit closer in class, when the teacher 'randomly' put the nearby students in groups, he has unintentionally group his students according to their ability. On his study performed on randomly assigned social groups at West Point, Lyle [14] (p. 292) stated that: "In general, it is difficult to assign an individual to a well-defined social 
group. This means it is even more difficult to view that assignment as untainted by selection bias". Therefore, grouping students randomly is not the prime selection when it comes to ensuring that students will be working in a rich and diverse environment that facilitates learning. According to the same research conducted by Chapman et al. [9], grouping students randomly resulted in inferior group dynamics ratings, slightly less positive attitudes about the group experience, and somewhat lower group outcome ratings, compared to those of student-selected groups.

\subsection{Homogeneously-Assigned Groups}

The process of educators assigning students into groups varies from natural variation (grouping randomly) to optimal policy (grouping based on some specific criteria). When students are put into groups with systematic allocation, two types of group formation may occur: homogeneous composition groups, and heterogeneous composition groups. Homogeneous groups are formed by instructors with the explicit goal of creating groups where each member is similar in ability, skills, or other characteristics (see, for example, Lejk et al. [15]). The data used to group students homogeneously usually comes from their records of academic performance, e.g., grades, marks, results, and attitudes. Johnson and Johnson [3] suggested that instructor-assigned groups usually result in the best student mix because teachers are better than students to form optimal combinations. Baer [16] made comparison of heterogeneously grouped and homogeneously grouped cooperative learning groups in six paired classes, taught by the same professor using matching syllabi and assignments. The author's findings suggested that homogeneously grouped students (who were grouped according to achievement on the first test given in the course) dramatically outperformed heterogeneously grouped students on the final examination. Specifically, high- or average-achieving students can be seen to benefit from homogeneous grouping, whereas low achievers did equally well whether their groups were homogeneously or heterogeneously formed. However, the context to Baer's findings was limited in a way that group work is conducted within class time and the performance on group work is not graded.

\subsection{Hetergeneously-Assigned Groups}

Another alternative of grouping students with organized allocation are heterogeneous composition groups. Heterogeneously-assigned groups-in contrast, are formed with the goal of creating balanced teams comprising individuals who represent a range of abilities, skills, major, gender, or ethnic background (Smith and Spindle [17]). The data used to put students in groups heterogeneously, similarly, come from their profiles or records of academic performance. Several computer-based tools have been developed to support automatic group formation with specific criteria in the field of e-learning [18]. There are certain advantages regarding the heterogeneous grouping of students in cooperative learning. For instance, inter-group relations are promoted when students have varying backgrounds. Wang's experiment [19] conducted on cross-cultural online collaboration groups between American and Taiwanese students suggested that cultural differences seemed to be the best learning materials for students to explore, despite the fact that other researchers viewed it as a difficulty. (Chang and Lim [20]; Kim and Bonk [21]). Baer and Baer [22] revealed that purposefully assigning undergraduates to promote heterogeneity in terms of racial, ethnic, and gender to make-up of groups may have positive effect on student achievement in cooperative learning, in comparison to student-selected groups. It can be seen that heterogeneously-assigned groups are often associated with the high achievement of nonacademic goals of cooperative learning, such as improving relations within the group. In addition, many cooperative learning methods recommend heterogeneous over homogeneous group composition as to reflect the diversity of student abilities and background in the class. Further research also suggests that elaborative thinking, providing and receiving explanations, and perspective in taking discussion are of a greater degree; these in turn lead to deeper understanding, better reasoning abilities, and accuracy in long-term retention (Johnson and Johnson [3]). Heterogeneous group composition also maximizes the opportunities for peer support 
and helpful mutual exchange, as suggested by Webb and Palincsar [23]. However, drawbacks of this instructor-assigned type of group are revealed when the groups encounter problems. The work in this kind of group is not as equally divided as in group of student-selected, with the major work falls on individuals who were left to assemble the (sometimes careless) work of others and individuals who took more responsibility than other group members preferred.

\section{Research Methodology}

We provide information on the research method used in this study. Specifically, the research design, research hypothesis, participants, research instrument, and the collection and analysis of data are clearly presented.

\subsection{Research Design}

This study follows quantitative design. The researcher explores preference of group formation methods of Course 40 and Course 41 students majoring in English Teacher Education and English Studies at Department of English, School of Education, Can Tho University. Additionally, the researcher investigates the differences (if any) in group dynamics, satisfaction of students, and cooperative learning outcome when four different grouping strategies are used.

\subsection{Research Questions}

The study is directed by the following questions:

1. What type of grouping method is preferred by seniors and juniors with majors in English at Can Tho University?

2. Do different group formation methods make a difference in terms of group dynamics, student's satisfaction, and achievement?

The detail of survey questions can be found in the Appendix A.

\subsection{Research Hypothesis}

In this study, the researchers hypothesized that:

- Juniors and seniors with majors in English at Can Tho University prefer student-selected groups over the others;

- Different methods of group assignment do make a perceivable difference on the nature of cooperative learning experience.

\subsection{Description of Population and Sample}

The research was conducted on English Teacher Education and English Studies students in April 2018 at Can Tho University - an accredited university in Can Tho city, Vietnam. Course selected for participation included Course 40 (seniors) and Course 41 (juniors). Being seniors and juniors means the participants have experienced various group formation methods in their language skills classes to hold certain ideas and preferences on them. The frequency of encountering each grouping strategy is also higher with seniors and juniors as they have taken plenty of classes that required working in teams. That assures adequate knowledge to make comparisons on different group formation methods.

\subsection{Data Collection}

The survey was distributed online using Google Forms and in hard copies and were collected from 100 respondents. 46 of the respondents submitted online answers and 54 responded directly with hard copies of the survey. The researcher gave detailed explanation on the purpose of the research and what the participants were expected to do in the instructions of the survey. The participants were also told that their responses were confidential and only used for the research purpose. 


\subsection{Data Analysis and Reliability}

Data analysis was put forth with Version 23 of Statistical Package for the Social Sciences (SPSS) which is highly trusted in analyzing data in the field of Social Science. The reader is referred to the SPSS user guide [24] and ([5] Section 4) for a sample use of the SPSS in the context of English learning and teaching.

The Cronbach's alpha that shows internal consistency for:

- $\quad$ group dynamics scale is alpha $=0.84$

- $\quad$ student's satisfaction scale is alpha $=0.82$,

- $\quad$ achievement scale is alpha $=0.74$

which has sufficient reliability (Nunnally [25]). One-way analysis of variance (ANOVA) was employed to determine whether the differences in means of measures between four group formation methods were significant.

\subsection{Research Instrument}

The instrument of this research is a survey consisting of twenty measures of group dynamics, student's satisfaction, and achievement of four group formation methods. Each measure is assessed with a series of semantic bipolar 5-point scales, ranging from " 1 " being "Strongly disagree" to " 5 " being "Strongly agree". Many of these measures were adapted from prior research comparing random assignment groups and self-selected groups (e.g., Chapman et al. [9]). A section for a group formation method other than the listed four is spared so that participants can freely add their answers. The survey is written in English and Vietnamese. The English version was distributed to the respondents with on-scene detailed instructions from the researcher to avoid misinterpretations.

\section{Results}

In this section, the results are presented based on the quantitative analysis of the data. The quantitative analysis includes processing the data using SPSS Statistic in order to find out the grouping strategy most favored by students, and whether the perceived differences on group dynamics, student's satisfaction and achievement exist under different group assignment methods.

\subsection{Student Grouping Method Preference}

As can be seen from the data of Tables 1 and 2, most respondents said they would like to choose their group partner(s) themselves when learning cooperatively (83\%). This corresponds with the figure of $84 \%$ respondents who chose Student-selected as their most preferred method to form a group. This suggests that student-selected is generally preferred by juniors and seniors with majors in English at Can Tho University. Although being statistically minor, there is $9 \%$ of the students said they would like the instructor to arrange them in groups, and $8 \%$ stated that they did not have preferences on whether their partners are assigned or selected themselves.

Table 1. Description of Student's Preference on Group Assigner.

\begin{tabular}{lc}
\hline Statement & Percentage of Respondents (\%) \\
\hline I would like to choose my partner(s) myself & 83.0 \\
I would like the teacher to assign my partner(s) for me & 9.0 \\
I have no preferences on who get to choose my partner(s) & 8.0 \\
\hline
\end{tabular}


Table 2. Description of Student's Preference on Group Formation Method.

\begin{tabular}{lc}
\hline Preferred Group Formation Method & Percentage of Respondents (\%) \\
\hline Student-selected & 84.0 \\
Randomly-assigned & 8.0 \\
Homogeneously-assigned & 3.0 \\
Heterogeneously-assigned & 5.0 \\
\hline
\end{tabular}

Table 3 reveals the preference of students the academic level of their cooperative learning partner. Most of the students who responded to the survey specified that they wanted their partners to have a higher or the same academic level than they did themselves ( $49 \%$ and $28 \%$, respectively). On the contrary, only $2 \%$ of the respondents expected the academic level of their groupmates to be lower than that of themselves. More than one fifth of the respondents did not take the academic level of their partners into account when joining a group.

Table 3. Description of Student's Preference on Partner's Academic Level.

\begin{tabular}{lc}
\hline Academic Level & Percentage of Response $(\%)$ \\
\hline Similar & 28.0 \\
Higher & 49.0 \\
Lower & 2.0 \\
Doesn't matter & 21.0 \\
\hline
\end{tabular}

\subsection{Impact of Group Assignment on Group Dynamics}

The data presented in Table 4 suggest that the method of group assignment did influence the perception of students on group dynamics, although not greatly or aggregately. Of the 9 measures of group dynamics, 1 was statistically different when the formation methods varied (3. At meetings, group went straight to work) and 1 was significantly different between student-selected groups and heterogeneously-assigned groups (8. Members trust each other's abilities).

Table 4. Mean Group Dynamic Measures Based on Method of Group Formation Method.

\begin{tabular}{|c|c|c|c|c|c|}
\hline Group Dynamic Measure * & Overall & $\begin{array}{l}\text { Student } \\
\text { Selected }\end{array}$ & $\begin{array}{l}\text { Randomly } \\
\text { Assigned }\end{array}$ & $\begin{array}{l}\text { Homogeneously } \\
\text { Assigned }\end{array}$ & $\begin{array}{c}\text { Heterogeneously } \\
\text { Assigned }\end{array}$ \\
\hline 1. Group used meeting time well & 3.34 & 3.44 & 3.27 & 3.30 & 3.19 \\
\hline 2. During meetings, group was task oriented & 3.51 & 3.48 & 3.56 & 3.25 & 3.72 \\
\hline 3. At meetings, group went straight to work & 3.24 & 3.09 & $3.41^{* * *}$ & 3.35 * & $3.47^{*}$ \\
\hline 4. Members were comfortable around each other & 3.50 & 3.91 & 3.04 & 3.15 & 3.13 \\
\hline 5. Group argued a lot & 3.15 & 3.05 & 3.35 & 3.35 & 3.19 \\
\hline 6. Group achieved harmony by avoiding disagreements & 3.19 & 3.19 & 3.23 & 3.00 & 3.22 \\
\hline 7. Work was equally divided among members & 3.49 & 3.59 & 3.50 & 3.05 & 3.25 \\
\hline 8. Members trust each other's abilities & 3.45 & 3.73 & 3.25 & 3.45 & 2.97 * \\
\hline 9. Members followed group's deadlines & 3.66 & 3.71 & 3.75 & 3.25 & 3.63 \\
\hline
\end{tabular}

ratings are based on a 5-point scale where $1=$ strongly disagree and $5=$ strongly agree. Significance of difference of randomly-assigned, homogeneously-assigned, heterogeneously-assigned compared to student-selected groups: ${ }^{*} p \leq 0.05,{ }^{* * *} p \leq 0.001$.

Compared to the members of in self-selected groups, members in groups which were assigned by instructors, either randomly or with systematic allocation, tended to go straight to work at group meetings. However, students reported having less trust in their partner(s)' abilities when working in heterogeneously-assigned groups, compared to when working in groups with partner(s) selected by themselves (means of 2.97 and 3.73, respectively). Although not statistically significant, homogeneously-assigned and student selected groups were regarded as the least task-oriented groups of the four assignments (mean 3.25 and 3.48, respectively), whereas this mean for heterogeneous groups remained the highest (3.72). 


\subsection{Impact of Group Assignment on Student's Satisfaction}

The method of group assignment had a very modest effect on the attitudes and satisfaction of students toward cooperative learning groups and experience as shown in Table 5. Students reported on seeing the experience of working in student-selected groups to be more valuable than the experience of team work in randomly-assigned groups (means 3.46 and 3.91, respectively).

The means of measures on student's satisfaction in self-selected groups are dominantly higher than those of the other three group forming methods. The lowest degree of satisfaction, however, is associated with homogeneously-assigned groups.

Table 5. Mean Student's Satisfaction Measures Based on Method of Group Formation Method.

\begin{tabular}{|c|c|c|c|c|c|}
\hline Student's Satisfaction Measure * & Overall & $\begin{array}{l}\text { Student } \\
\text { Selected }\end{array}$ & $\begin{array}{c}\text { Randomly } \\
\text { Assigned }\end{array}$ & $\begin{array}{c}\text { Homogeneously } \\
\text { Assigned }\end{array}$ & $\begin{array}{c}\text { Heterogeneously } \\
\text { Assigned }\end{array}$ \\
\hline 10. The overall attitude towards the group is good & 3.44 & 3.62 & 3.25 & 3.20 & 3.37 \\
\hline 12. Group work was an enjoyable experience & 3.50 & 3.65 & 3.21 & 3.40 & 3.59 \\
\hline 13. Group work was effective & 3.40 & 3.56 & 3.31 & 3.20 & 3.19 \\
\hline 14. I was satisfied with this group work & 3.45 & 3.53 & 3.27 & 3.50 & 3.44 \\
\hline
\end{tabular}

ratings are based on a 5-point scale where $1=$ strongly disagree and $5=$ strongly agree. Significance of difference of randomly-assigned compared to student-selected groups: * $p \leq 0.05$.

\subsection{Impact of Group Assignment on Outcome and Achievement}

In Table 6, there were no significant differences on the perception of group work outcome and achievement when working in groups with different group assignment.

Table 6. Mean Achievement Measures Based on Method of Group Formation Method.

\begin{tabular}{|c|c|c|c|c|c|}
\hline Achievement Measure & Overall & $\begin{array}{l}\text { Student } \\
\text { Selected }\end{array}$ & $\begin{array}{c}\text { Randomly } \\
\text { Assigned }\end{array}$ & $\begin{array}{c}\text { Homogeneously } \\
\text { Assigned }\end{array}$ & $\begin{array}{c}\text { Heterogeneously } \\
\text { Assigned }\end{array}$ \\
\hline 16. Group achieved primary goal(s) & 3.71 & 3.82 & 3.56 & 3.65 & 3.63 \\
\hline 17. Group got good grades & 3.47 & 3.51 & 3.50 & 3.20 & 3.47 \\
\hline 18. Group work helped me improve my teamwork skills & 3.76 & 3.95 & 3.60 & 3.65 & 3.56 \\
\hline 19. I made new friend(s) & 3.44 & 3.38 & 3.54 & 3.45 & 3.44 \\
\hline 20. Group work was an effective learning tool & 3.64 & 3.66 & 3.50 & 3.75 & 3.72 \\
\hline
\end{tabular}

ratings are based on a 5 -point scale where $1=$ strongly disagree and $5=$ strongly agree.

However, it is noteworthy to consider the relatively positive ratings across the measures of performance, with most of the means above 3.41. These findings suggest that students seem to satisfy with their academic outcome associated with cooperative learning.

Compared to Baer's [16] research, which suggested that homogeneously assigning students into groups results in higher academic achievement in high, or average achievers while doing no harm to that of low achievers, the result showed little difference between the academic performance of homogeneously and heterogeneously assigned groups.

To sum up, Tables 1 and 2 confirm that student-selected grouping method is prevalent and preferred among students. However, the fact that most students would rather have group partners of higher academic level than that of themselves (i.e., heterogeneous group formation) was made clear in Table 3. Tables 4-6 compare the impact of four group assignment methods in terms of group dynamics, students' satisfaction, and group achievement, revealing that only student-selected groups holds the significant difference compared to the other three which is simply visualized in Figure 1. 


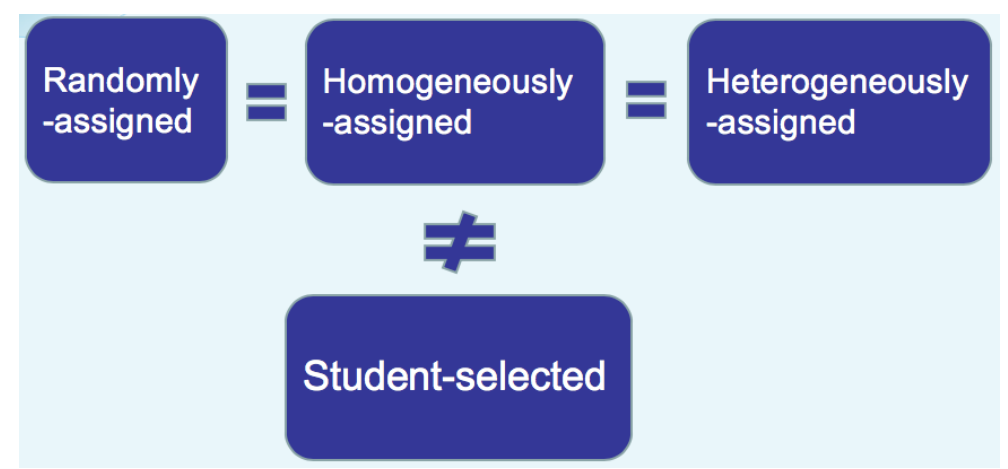

Figure 1. Student-selected is the only grouping method that bears significant differences compared to each of the three other grouping methods.

\section{Discussions of Findings}

\subsection{Grouping Method Preferences of English Majored}

The result of the study indicates that the grouping method of student-selected is the most favored by juniors and seniors with majors in English at Can Tho University, with $83 \%$ of the respondents wanted to form group themselves and $84 \%$ of the respondents reported on having student-selected grouping method is their favorite way to form a group. This result supports the hypothesis given at the beginning of the research. It can be observed from the data that English majors at Can Tho University preferred heterogeneity when it comes to choosing their partner(s), with $51 \%$ of the respondents chose to have partner(s) of different academic levels (49\% higher and $2 \%$ lower). By expecting their partners to possess higher academic achievements, most students seem to view cooperative learning as a chance to learn from their peers. This suggests a positive mindset of students when being assigned to learning cooperatively.

\subsection{Impact of Student-Selected Method on Group Experience}

Student-selected group formation method is also the only method that has statistically significant differences on the nature of team work, compared to the other three methods. In terms of group dynamics, the data suggest that student-selected groups are thought to be better at maintaining a harmonious team-working atmosphere, however, is less task-oriented than groups of the other three grouping methods. This matches the survey conducted by Chapman et al. [9] which revealed distracting tendency of self-selected groups. The reason for this is probably because of the degree to which group partners knew each other before group work. Good friends would likely to discuss topics of mutual interests at group meetings rather than the assigned task itself. This is also the case for homogeneously-assigned groups, with the mean of task-orientation being the lowest. Regarding the measures on student's satisfaction, all means of the student-selected groups was higher than those of randomly-assigned, homogeneously-assigned, and heterogeneously-assigned groups. It is obvious that working in groups chosen by the students themselves results in positive feelings toward group experience. Although there is the distinction is minor, academic achievements of student-selected groups are higher in ratings. However, social outcome ratings related to employing cooperative learning as a learning tool is lower than those of the other three methods. The reason for this was not taken into account in this research, but it may be because students had already known each other before working together as a group, so certain social procedures such as getting to know each other or compromising are omitted. Overall, student-selected groups are not "A Profile for Failure" as Feichtner and Davis [11] (p. 70) stated. In fact, report on student's attitudes showed that favorable ratings on group dynamics, learner's satisfaction, and academic accomplishments are connected to letting the students choose the groups themselves. 


\subsection{Impact of Randomly-Assigned, Homogeneously-Assigned and Heterogeneously-Assigned Method on Group Experience}

No statistically distinctive variation of ratings on group dynamics, learner's satisfaction, and cooperative learning outcome was determined between the three group assignments of randomly-assigned, homogeneously-assigned and heterogeneously-assigned. However, in contrast to Baer's [16] report, this study shows no superiority in terms of achievement and outcome perception of homogeneously-assigned groups over heterogeneously-assigned groups.

\section{Conclusions and Recommendations}

Our findings have indicated that that the student-selected is the most preferred grouping strategy among the four: student-selected, randomly-assigned, homogeneously-assigned, and heterogeneously-assigned by seniors and juniors with majors in English at Can Tho University. Group formation methods made little perceivable differences on group outcome and achievement. However, modest distinction was found in group dynamics and student's satisfaction on group work suggesting that members of student-selected groups had more trust in each other abilities and took group work as a valuable experience. Group members of student-selected groups, nonetheless, were less competent at managing meeting time. Overall, there are high (i.e., positive) ratings on measures of self-selected groups. Randomly-assigned, homogeneously-assigned, and heterogeneously-assigned differ significantly in one or two measures compared to student-selected groups, however, not to one another.

There are two limitations in this study. First, the number of samples collected for each grouping strategy was not equal. This is because fewer respondents reported on having encountered randomly-assigned, homogeneously-assigned, heterogeneously groups as often as they have with student-selected groups. This may reduce the statistical reliability of the result due to insufficient number of samples. Second, this study only dealt with the perception and attitudes of student toward different grouping methods. The internal reasons to why the measures differ have been left undetermined.

The importance of group assignment should be taken into account before deciding on employing cooperative learning as a teaching strategy. Classroom-wise, with the knowledge of the properties of different group types of English majors at Can Tho University, instructors can now make adjustments to their grouping processes accordingly. For example, if student-selected groups are known to have problems with focusing on the task at meetings, instructors should provide reminders or tips that address the issue.

The present study only examined the perceptive properties of each grouping strategies. Experimental research on the practice of four group assignments should be carried out to ascertain the trends and the differences. These are the subjects of our ongoing research project.

Author Contributions: The outline and ideas of the study were led by H.N. The first author also designed and carried out the survey. Both authors quantitatively analyzed the data and completed the paper.

Funding: This research received no external funding.

Acknowledgments: The authors gratefully acknowledge the valuable comments and suggestions from the anonymous referees.

Conflicts of Interest: The authors declare no conflict of interest.

\section{Appendix A. Complete Survey Questions}

The purpose of this questionnaire is to discover learners' opinions on four group formation methods in cooperative learning, including student-selected groups, randomly-assigned groups, homogeneously-assigned groups, and heterogeneously assigned groups. Your personal information and opinions about the two group formation methods will not be shared with anyone else and used only for research purpose. 


\section{*: Required}

1. Your major is (mark only one oval):*

- English Teacher Education

- English Studies

- None of the above (Kindly end the survey here). After the last question in this section, stop filling out this form.

2. Your course is (mark only one oval):*

- $\quad$ Course 40

- $\quad$ Course 41

- None of the above (Kindly end the survey here). Stop filling out this form.

Part A: Grouping method preferences

GMP1. When learning in groups, how would you like to choose your partners? ${ }^{*}$ Mark only one oval.

- I would like to choose my partner(s) myself.

- I would like the teacher to assign my partner(s) for me.

- I have no preference on who gets to choose my partner(s).

- Other:

GMP2. Would you like your partner(s) to have the same or different (higher or lower) academic level, skills, and background as you do? * Mark only one oval.

- I'd like my partner(s) to have the same level as I do.

- I would like my partner(s) to have higher level than I do.

- I would like my partner(s) to have lower level than I do.

- I don't care about the academic levels of my partner(s).

GMP3. Which group forming method have you encountered in your English classes at Can Tho University? * Check all that apply.

- Student-selected. (Students choose partners themselves.)

- Randomly-assigned. (Teachers group students randomly.)

- Homogenously-assigned. (Teachers purposefully group students with the same academic level, skills, or background in one group.)

- Heterogeneously-assigned. (Teachers purposefully group students with different academic level, skills, or background in one group.)

- Other:

If you have chosen: Student-selected, answer PART B. Randomly-assigned, answer PART C. Homogeneously-assigned, answer PART D. Heterogeneously-assigned, answer PART E. Other, answer PART F. If you have chosen more than one answer, kindly answer all the corresponding parts. For example, if you gave encountered student-selected groups and heterogeneously-assigned groups, answer BOTH Part B and Part E.

\section{Part B: Measures on Student-selected Groups}

Answer Part B if you have encountered STUDENT-SELECTED GROUPS (Students choose partners themselves.) Please mark the answers that best express what you think, according to the following scale: SA (Strongly agree), A (Agree), N (Neutral), D (Disagree), SD (Strongly disagree). There is no right or wrong answer.

Group Dynamics. (Mark only one per row: SD D N A SA) 
- Group used meeting time well.

- During meetings, group was task oriented.

- At meetings, group went straight to work.

- Members were comfortable around each other.

- Group argued a lot.

- Group achieved harmony by avoiding disagreements.

- Work was equally divided among members.

- Members trust each other's abilities

- Members followed group's deadlines.

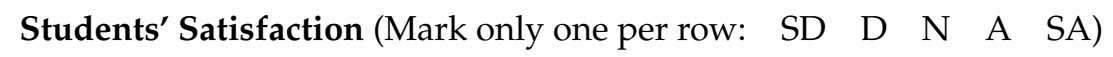

- The overall attitude towards the group is good.

- Group work was a valuable experience.

- Group work was an enjoyable experience.

- Group work was effective.

- I was satisfied with this group work.

- I felt useful and helpful as a member of the group.

Academic Achievements (Mark only one per row: SD $\quad$ D $\quad N \quad$ A $\quad$ SA)

- Group achieved primary goal(s).

- Group got good grades.

- Group work helped me improve my teamwork skills.

- I made new friend(s).

- Group work was an effective learning tool.

PART C: Measures on Randomly-assigned Groups

Answer Part $C$ if you have encountered RANDOMLY-ASSIGNED GROUPS. (Teachers group students randomly.) Please mark the answers that best express what you think, according to the following scale: SA (Strongly agree), A (Agree), N (Neutral), D (Disagree), SD (Strongly disagree). There is no right or wrong answer.

Group Dynamics (Mark only one per row: SD D N A SA)

- $\quad$ Group used meeting time well.

- During meetings, group was task oriented.

- At meetings, group went straight to work.

- Members were comfortable around each other.

- Group argued a lot.

- Group achieved harmony by avoiding disagreements.

- Work was equally divided among members.

- Members trust each other's abilities

- Members followed group's deadlines.

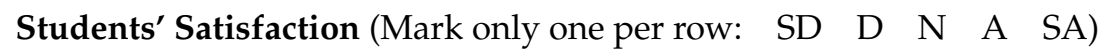

- The overall attitude towards the group is good.

- Group work was a valuable experience.

- Group work was an enjoyable experience.

- Group work was effective.

- I was satisfied with this group work. 
- I felt useful and helpful as a member of the group.

Academic Achievements (Mark only one per row: SD D N A SA)

- Group achieved primary goal(s).

- Group got good grades.

- Group work helped me improve my teamwork skills.

- I made new friend(s).

- Group work was an effective learning tool.

PART D: Measures on Homogenously-assigned Groups

Answer Part D if you have encountered HOMOGENEOUSLY-ASSIGNED GROUPS (Teachers purposefully group students with the same academic level, skills, or background in one group). Please mark the answers that best express what you think, according to the following scale: SA (Strongly agree), A (Agree), N (Neutral), D (Disagree), SD (Strongly disagree). There is no right or wrong answer.

Group Dynamics (Mark only one per row: SD D N A SA)

- $\quad$ Group used meeting time well.

- During meetings, group was task oriented.

- At meetings, group went straight to work.

- Members were comfortable around each other.

- Group argued a lot.

- Group achieved harmony by avoiding disagreements.

- Work was equally divided among members.

- Members trust each other's abilities

- Members followed group's deadlines.

Students' Satisfaction (Mark only one per row: SD D N A SA)

- The overall attitude towards the group is good.

- Group work was a valuable experience.

- Group work was an enjoyable experience.

- Group work was effective.

- I was satisfied with this group work.

- I felt useful and helpful as a member of the group.

Academic Achievements (Mark only one per row: SD $\quad$ D $\quad N \quad$ A $\quad$ SA)

- Group achieved primary goal(s).

- Group got good grades.

- Group work helped me improve my teamwork skills.

- I made new friend(s).

- Group work was an effective learning tool.

PART E: Measures on Heterogeneously-assigned Groups

Answer Part E if you have encountered HETEROGENEOUSLY-ASSIGNED GROUPS (Teachers purposefully group students with different academic level, skills, or background in one group.) Please mark the answers that best express what you think, according to the following scale: SA (Strongly agree), A (Agree), N (Neutral), D (Disagree), SD (Strongly disagree). There is no right or wrong answer.

Group Dynamics (Mark only one per row: SD D N A SA)

- $\quad$ Group used meeting time well. 
- During meetings, group was task oriented.

- At meetings, group went straight to work.

- Members were comfortable around each other.

- Group argued a lot.

- Group achieved harmony by avoiding disagreements.

- Work was equally divided among members.

- Members trust each other's abilities

- Members followed group's deadlines.

Students' Satisfaction (Mark only one per row: SD D N A SA)

- The overall attitude towards the group is good.

- Group work was a valuable experience.

- Group work was an enjoyable experience.

- Group work was effective.

- I was satisfied with this group work.

- I felt useful and helpful as a member of the group.

Academic Achievements (Mark only one per row: SD D N A SA)

- Group achieved primary goal(s).

- Group got good grades.

- Group work helped me improve my teamwork skills.

- I made new friend(s).

- Group work was an effective learning tool.

PART F: Measures on other groups

Answer Part $\mathrm{F}$ if you have encountered ANOTHER TYPE OF GROUP FORMATION. Please mark the answers that best express what you think, according to the following scale: SA (Strongly agree), A (Agree), N (Neutral), D (Disagree), SD (Strongly disagree). There is no right or wrong answer.

Group Dynamics (Mark only one per row: SD D N A SA)

- $\quad$ Group used meeting time well.

- During meetings, group was task oriented.

- At meetings, group went straight to work.

- Members were comfortable around each other.

- Group argued a lot.

- Group achieved harmony by avoiding disagreements.

- Work was equally divided among members.

- Members trust each other's abilities.

- Members followed group's deadlines.

Students' Satisfaction (Mark only one per row: $\quad$ SD $\quad$ D $\quad$ N A $\quad$ SA)

- The overall attitude towards the group is good.

- Group work was a valuable experience.

- Group work was an enjoyable experience.

- Group work was effective.

- I was satisfied with this group work.

- I felt useful and helpful as a member of the group.

Academic Achievements (Mark only one per row: SD $\quad$ D $\quad N \quad$ A $\quad$ SA) 
- Group achieved primary goal(s).

- Group got good grades.

- Group work helped me improve my teamwork skills.

- I made new friend(s).

- Group work was an effective learning tool.

Part G: Favorite Grouping Method

Which group formation method is your favorite? ${ }^{*}$ (Mark only one oval)

- Student-selected. (Students choose partners themselves.)

- Randomly-assigned. (Teachers group students randomly.)

- Homogenously-assigned. (Teachers purposefully group students with the same academic level, skills, or background in one group.)

- Heterogeneously-assigned. (Teachers purposefully group students with different academic level, skills, or background in one group.)

- Other:

\section{References}

1. Hsu, Y.-C. Evaluation theory in problem-based learning approach. Presented at the National Convention of the Association for Educational Communications and Technology, Houston, TX, USA, 17-18 July 2003.

2. Johnson, D.W.; Johnson, R.T. Cooperative learning and social. In Interdependence Theory; Tindale, R.S., Theory and Research on Small Groups, Eds.; Plenum Press: New York, NY, USA, 1998; pp. 9-35.

3. Johnson, D.W.; Johnson, R.T. Learning Together and Along: Cooperative, Competitive, and Individualistic Learning, 5th ed.; Allyn \& Bacon: Boston, MA, USA, 1999.

4. Azizinezhad, M.; Hashemi, M.; Darvishi, S. Application of Cooperative Learning in EFL Classes to Enhance the Students' Language Learning. Procedia Soc. Behav. Sci. 2013, 93, 138-141. [CrossRef]

5. Chen, H.-Y.; Goswami, J. Structuring Cooperative Learning in Teaching English Pronunciation. Engl. Lang. Teach. 2011, 4, 26-32. [CrossRef]

6. McCafferty, S.; Jacobs, G.M.; Iddings, A.C.D. Cooperative Learning and Second Language Teaching; Cambridge English Education; Cambridge University Press: Cambridge, UK, 2006. ISBN 9780521606646.

7. Kagan, S. Cooperative Learning; Kagan Publishing: San Clemente, CA, USA, 1994.

8. Hishina, M.; Okada, R.; Suzuki, K. Group formation for web-based collaborative learning with personality information. Int. J. E-Learn. 2005, 4, 351-364.

9. Chapman, K.J.; Meuter, M.; Toy, D.; Wright, L. Can't We Pick our Own Groups? The Influence of Group Selection Method on Group Dynamics and Outcomes. J. Manag. Educ. 2006, 30, 557-569. [CrossRef]

10. Swanson, Z.L.; Gross, N.J.; Kramer T. Alternative models of study group formation and student examination performance. Account. Educ. J. 1998, 10, 1-11.

11. Feichtner, S.B.; Davis, E.A. Why some groups fail: A survey of students experiences with learning groups. J. Manag. Educ. 1984, 9, 58-73. [CrossRef]

12. Hilton, S.; Phillips F. Instructor-assigned and student-selected groups: A view from inside. Account. Assoc. 2008. [CrossRef]

13. Nhan, T.A. Cooperative Learning Activities with a Focus on Geometry Applications in a Basic Math \& Pre-Algebra Class, Bay Area Active Learning Workshop Proceeding. 2018. Available online: https: / / tinyurl.com/NHAN18-PreAlg (accessed on 10 May 2018).

14. Lyle, D.S. Estimating and interpreting peer and role model effects from randomly assigned social groups at West Point. Rev. Econ. Stat. 2007, 89, 289-299. [CrossRef]

15. Lejk, M.; Wyvill M.; Farrow S. Group assessment in systems analysis and design: A comparison of the performance of streamed and mixed-ability groups. Assess. Eval. Higher Educ. 1999, 24, 5-14. [CrossRef]

16. Baer, J. Grouping and achievement in cooperative learning. Coll. Teach. 2003, 51, 169-175. [CrossRef]

17. Smith, J.; Spindle R.M. The impact of group formation in a cooperative learning environment. J. Accoun. Educ. 2007, 25, 153-167. [CrossRef] 
18. Christodoulopoulos, C.E.; Papanikolaou, K.A. A Group Formation Tool in an E-Learning Context. In Proceedings of the 19th IEEE International Conference on Tools with Artificial Intelligence(ICTAI 2007), Patras, Greece, 29-31 October 2007. [CrossRef]

19. Wang, C. Instructional design for cross-cultural online collaboration: Grouping strategies and assignment design. Austr. J. Educ. Technol. 2011, 27. [CrossRef]

20. Chang, T.-T.; Lim, J. Cross-Cultural Communication and Social Presence in Asynchronous Learning Processes. JSTOR 2002, 1, 83-105.

21. Kim, K.-J.; Bonk, C.J. Cross-cultural comparisons of online collaboration. J. Comput. Med. Commun. $2002,8$. [CrossRef]

22. Baer, J.; Baer, S.K. Group structure in cooperative learning. Presented at the Eighth National Conference on College Teaching and Learning, Jacksonville, FL, USA, 16-19 April 1997.

23. Webb, N.M.; Palincsar, A.S. Group processes in the classroom. In Handbook of Educational Psycholog; Berliner, D.C., Calfee, R.C., Eds.; Simon \& Schuster: New York, NY, USA, 1996; pp. 841-873.

24. Bryman, A.; Cramer, D. Quantitative Data Analysis with IBM SPSS 17, 18 and 19: A Guide for Social Scientists; Routledge: New York, NY, USA, 2011.

25. Nunnally, J.C. Psychometric Theory, 2nd ed.; McGraw-Hill: New York, NY, USA, 1978.

(C) 2019 by the authors. Licensee MDPI, Basel, Switzerland. This article is an open access article distributed under the terms and conditions of the Creative Commons Attribution (CC BY) license (http:/ / creativecommons.org/licenses/by/4.0/). 